\title{
Mixing ratios and eddy covariance flux measurements of volatile organic compounds from an urban canopy (Manchester, UK)
}

\author{
B. Langford ${ }^{1}$, B. Davison ${ }^{1}$, E. Nemitz ${ }^{2}$, and C. N. Hewitt ${ }^{1}$ \\ ${ }^{1}$ Lancaster Environment Centre, Lancaster University, Lancaster, LA1 4YQ, UK \\ ${ }^{2}$ Centre for Ecology \& Hydrology (CEH) Edinburgh, Bush Estate, Penicuik, EH26 0QB, UK \\ Received: 13 November 2007 - Published in Atmos. Chem. Phys. Discuss.: 8 January 2008 \\ Revised: 17 February 2009 - Accepted: 24 February 2009 - Published: 19 March 2009
}

\begin{abstract}
Mixing ratios and fluxes of six selected volatile organic compounds (VOCs) were measured above the city of Manchester (UK) during the summer of 2006. A proton transfer reaction-mass spectrometer was used for the measurement of mixing ratios, and fluxes were calculated from these using both the disjunct and the virtual disjunct eddy covariance techniques. The two flux systems, which operated in alternate half hours, showed good agreement, with $R^{2}$ values ranging between 0.74 and 0.9 for the individual analytes. On average, fluxes measured in the disjunct mode were approximately $20 \%$ lower than those measured in the virtual mode. This difference is due to both the dampening of the VOC signal by the disjunct flux sampler and carry over from one sample to the next. Correcting for these effects reduced the difference to less than 7\%. Observed fluxes are thought to be largely controlled by anthropogenic sources, with vehicle emissions the major contributor. However, both evaporative and biogenic emissions may account for some of the VOCs present. Concentrations and fluxes of the oxygenated compounds were highest on average, ranging between 0.15 to $1 \mathrm{mg} \mathrm{m}^{-2} \mathrm{~h}^{-1}$; the fluxes of aromatic compounds were lower, between 0.12 to $0.28 \mathrm{mg} \mathrm{m}^{-2} \mathrm{~h}^{-1}$. The observed fluxes were up-scaled to give city wide emission estimates for each compound and the results compared to estimates made by the National Atmospheric Emission Inventory (NAEI) for the same flux footprint. Fluxes of toluene and benzene compared most closely differing by approximately $50 \%$, while in contrast the oxygenated fluxes were found to be between 3.6-6.3 times larger than the annual average predicted by the NAEI.
\end{abstract}

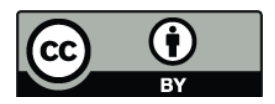

Correspondence to: C. N. Hewitt (n.hewitt@lancaster.ac.uk)

\section{Introduction}

The compilation of spatially and temporally detailed inventories for the emission of anthropogenic volatile organic compounds (VOCs) from urban areas is a necessary requirement for air quality regulatory purposes, effects assessment and research. Current emission estimates are associated with large degrees of uncertainty (Friedrich and Obermeier, 1999) which may limit their usefulness. Much of this uncertainty can be attributed to the large variety of different source categories which contribute to urban VOC emissions, which can be difficult to characterise and validate. Rather than taking a "bottom-up" inventory approach, an alternative is to make direct micrometeorologically based measurements which can integrate observations of wind speed and scalar concentrations to give a city-wide estimate of pollutant emission rates (Nemitz et al., 2002; Dorsey et al., 2002; Velasco et al, 2005; Martin et al., 2008; Famulari et al., 2009).

Currently, the eddy covariance (EC) technique is considered the most direct micrometeorological method available for estimating surface/atmosphere exchange fluxes, as it measures the turbulent flux directly, without reliance on any empirical parameterisations. This approach requires high frequency measurements (typically in the order of $5-20 \mathrm{~Hz}$ ) of both vertical wind speed and concentration (or mixing ratios) to resolve all eddies that contribute to vertical transport (Lenschow, 1995). Although this technique is now well established for the measurement of some trace gases, such as $\mathrm{CO}_{2}$ and $\mathrm{H}_{2} \mathrm{O}$ (Aubinet et al., 2001), its application to VOC fluxes has been restricted because of the slow response times of most VOC sensors.

A number of alternative micrometeorological approaches have been developed which relax the demands placed upon instrument response times. The technique most commonly applied to VOCs is the relaxed eddy accumulation

Published by Copernicus Publications on behalf of the European Geosciences Union. 
method (REA), a conditional sampling technique where samples of air are directed into an up or down draught reservoir according to the sign of the vertical wind velocity at the time of sampling (Businger and Oncley, 1990). Air from each reservoir is subsequently analysed off-line and a flux is calculated from the difference in concentration generated between the two reservoirs. Unlike the eddy covariance method, REA is not a direct measure of the flux as it relies on empirical parameterisation. Furthermore, there is no scope for retrospective corrections to the coordinate frame (Bowling et al., 1998). Despite these drawbacks, the REA method has been successfully applied to a range of vegetation types including grass land (Olofsson et al., 2003), forests (Schween et al., 1997; Gallagher et al., 2000; Tani et al., 2002; Greenberg et al., 2003; Ciccioli et al., 2003; Friedrichs et al., 1999) and lately in an urban study (Park et al., 2008).

More recently a second technique, disjunct eddy covariance (DEC) (Rinne et al., 2001; Warneke et al., 2002; Turnipseed et al., 2009), has been developed for "relaxed" flux measurement. Rather than measuring at high frequencies as in EC, in DEC the flux is calculated using a sub-set of a continuous time series. In order to retain the flux contributions carried by small scale eddies, DEC utilises nearinstantaneous grab samples of air which are aspirated into a storage reservoir at regular intervals. The "dead" time between the sampling periods is then used to analyse the air at a rate suitable for the gas analyser. The discontinuous dataset generated can be used to give high precision flux information, which is numerically similar to the EC approach, but with reduced statistics (Grabmer et al., 2004). The DEC approach is particularly useful for sensors with a response time of 1 to $20 \mathrm{~s}$.

With the advent of quadrupole mass spectrometers (QMS) for the use of atmospheric composition measurements, a range of analysers is now becoming available that can provide fast measurements (as determined by the dwell time on a given $m / z$ ), which is nevertheless discontinuous (as the QMS scans through a range of $m / z$ 's). One such instrument is the proton transfer reaction-mass spectrometer (PTR-MS; Ionicon $\mathrm{GmbH}$; Innsbruck, Austria) which allows for the measurement of most VOCs with good sensitivity (10 ppt) and fast response times ( $200 \mathrm{~ms}-1 \mathrm{~s})$.

The quadrupole mass spectrometer in the PTR-MS can be programmed to scan over a small suite of masses in what is termed a scan cycle. Although in theory the instrument has a sufficient response time to be compatible with the eddy covariance method, in reality the quadrupole can only scan one mass at a time; therefore the dataset returned on completion of each duty cycle is in effect disjunct.

To optimise flux measurement approaches for these kind of data, the DEC concept has been developed further to calculate fluxes from the discontinuous time-series at each $\mathrm{m} / \mathrm{z}$ by pairing up each concentration measurement with the associated wind measurement in software, a process known as virtual disjunct eddy covariance (vDEC) (Karl et al.,
2001, 2002; Spirig et al., 2005; Lee et al., 2006; Ammann et al., 2006; Brunner et al., 2007). The advantage of this technique is that air can be sampled directly into the instrument, as individual masses are measured at a sufficiently fast rate: therefore no additional sampling system is required. Furthermore, analysis times are shorter than in DEC, allowing more data points to be collected during each averaging period and reducing the statistical uncertainty associated with the use of a discontinuous time series by averaging over a larger number of eddy motions. However, shorter dwell times can lead to increased random error in individual concentration measurements, therefore a balance must be found between analysis times and measurement frequency.

The vDEC method has been successfully applied to give VOC flux estimates over vegetation canopies, including grassland (Karl et al., 2001; Ammann et al., 2006; Brunner et al., 2007), forests (Karl et al., 2002; Spirig et al., 2005; Lee et al., 2006), and over an urban environment (Velasco et al., 2005).

In the current study we deployed both the DEC and vDEC techniques for the measurement of a range of VOCs above the city of Manchester (UK). The recorded data were then used to calculate city-wide emission fluxes which were compared to the UK National Atmospheric Emission Inventory (NAEI) for Manchester (http://www.naei.org.uk/datachunk. php?f_datachunk_id=174).

The NAEI, as with most emission inventories, is compiled using a bottom-up approach, where combinations of reported and estimated emissions across numerous source sectors are used to provide a spatially disaggregated $(1 \times 1 \mathrm{~km})$ emission inventory. The uncertainty associated with these estimates is dependent on the ratio of reported to estimated (modelled) data, and hence for compounds such as VOCs, where reported emissions are limited and uncertainty levels are high, micrometeorological methods offer a useful alternative and/or validation.

\section{Methods}

\subsection{Measurement site and general setup}

The work presented here formed part of the UK CityFlux project, which aimed to (i) directly measure pollutant emissions from urban areas, (ii) investigate controls of these emissions, (iii) derive emission factors relative to $\mathrm{CO}_{2}$ and $\mathrm{CO}$ and (iv) study pollutant transformation by comparing fluxes at the plume, street canyon and urban canopy scale. During the summer of 2006, micrometeorological measurements of VOC emissions were made over the city of Manchester, together with measurements of fluxes and concentrations of VOCs, aerosols, $\mathrm{O}_{3}, \mathrm{CO}_{2}$ and $\mathrm{H}_{2} \mathrm{O}$, as well as mobile measurements with a mobile laboratory, measurements in a street canyon, tracer releases and aircraft-borne measurements. The VOC flux measurements were taken from 
the roof of Portland Tower $\left(53^{\circ} 28^{\prime} 41^{\prime \prime} \mathrm{N} ; 2^{\circ} 14^{\prime} 18^{\prime \prime} \mathrm{W}\right)$, an $80 \mathrm{~m}$ tall, rectangular $(46 \mathrm{~m} \times 16 \mathrm{~m})$ office block, which is located in central Manchester. The building is situated on Portland Street, which is approximately $600 \mathrm{~m}$ distance from the Arndale centre, (the city's principal shopping district) $475 \mathrm{~m}$ from Piccadilly railway station, (the north-west's busiest station), and $100 \mathrm{~m}$ from the China Town district (a concentrated area of restaurants). The office block is surrounded by trafficked streets on three sides and a multi-storey car park on the other. The buildings in the immediate vicinity of the tower are predominately commercial thus giving the site an urban classification of 2 according to the criteria described by Oke (2006) (intensively developed high density urban area with 2-5 storey, attached or very close-set buildings often of brick or stone, e.g. old city core).

The roof of Portland Tower is not uniformly flat but has three levels. On the lowest level a small shed was erected which housed the PTR-MS. The second level, $2 \mathrm{~m}$ above, contained a utility substation $(20 \mathrm{~m} \times 10 \mathrm{~m})$ which was used to house the sonic anemometer signal box. The roof of the substation was used as the foundation for a $15 \mathrm{~m}$ mast which was fitted to the north west facing wall and instrumented with a sonic anemometer (Solent Research R3, Gill Instruments Ltd, Lymington, Hants, UK) and Teflon gas inlet line $\left(1 / 2^{\prime \prime} \mathrm{OD} ; 0.38^{\prime \prime} \mathrm{ID}\right)$. The mast was erected to get above the wake effects generated from both the edges of the building and the inhomogeneous roof surface and increased the effective measurement height to $95 \mathrm{~m}$ above street level. The anemometer and sample inlet were therefore $13 \mathrm{~m}$ above the highest part of the roof. Particle number fluxes from this site have been presented by Martin et al. (2008).

Fluxes were measured between 5 and 20 June 2006. During the first few days of measurements (5th-10th) a high pressure system was centred over Northern Ireland which dominated the weather during this period, with mostly dry conditions, clear skies and temperatures between $16-30^{\circ} \mathrm{C}$. Between 13th-16th a cold front slowly moved across Southern England and during this time temperatures at the measurement tower dropped to a maximum of $24^{\circ} \mathrm{C}$ and a minimum of $14^{\circ} \mathrm{C}$ on 16 th. For the later part of the campaign, temperatures slowly increased as a high pressure ridge moved in behind the cold front, increasing the average temperature to $21^{\circ} \mathrm{C}$. Throughout the campaign the wind direction shifted between SW and NNE, but also came from the SEE at certain times. The wind speed ranged between 0.4$11.2 \mathrm{~m} \mathrm{~s}^{-1}$, with an average of $3.3 \mathrm{~m} \mathrm{~s}^{-1}$ (based on 30-min averages).

2.2 The proton transfer reaction mass spectrometer (PTR-MS)

A PTR-MS instrument (Ionicon Analytik, Austria) was used for the measurement of VOC concentrations. Detailed descriptions of this instrument can be found elsewhere (Lindinger et al., 1998; Hayward et al., 2003; de Gouw and
Warneke., 2007), therefore only a brief account of the instrument and setup will be given here.

The PTR-MS used was an Ionicon standard model, containing two turbo-molecular pumps, a $9.6 \mathrm{~cm}$ long drift tube (stainless steel rings) and heated silico-steel inlet, which drew air at a rate of $0.151 \mathrm{~min}^{-1}$. The quadrupole was programmed to sequentially scan through a suite of six protonated target compounds: methanol $(\mathrm{m} / z$ 33), acetaldehyde $(m / z 45)$, acetone $(m / z 59)$, isoprene/furan $(m / z 69)$, benzene $(\mathrm{m} / \mathrm{z}$ 79) and toluene $(\mathrm{m} / \mathrm{z}$ 93). In addition to these compounds, the primary ion count, measured at $m / z 21\left(\mathrm{H}_{3}^{18} \mathrm{O}^{+}\right)$and two reagent cluster ions, $\mathrm{m} / \mathrm{z} 37$ $\left(\mathrm{H}_{3}^{16} \mathrm{O}^{+}\left(\mathrm{H}_{2}^{16} \mathrm{O}^{+}\right)\right)$and $m / z 55\left(\mathrm{H}_{3}^{16} \mathrm{O}^{+}\left(\mathrm{H}_{2}^{16} \mathrm{O}^{+}\right)_{2}\right)$ were also recorded. A further mass, $m / z 25$, was used at the start of each measurement cycle as a spacer to ensure the monitored air did not contain residues from the previous sample.

During the measurement period drift tube parameters pressure, temperature and voltage were held constant at 2 mbar, $45{ }^{\circ} \mathrm{C}$ and $600 \mathrm{~V}$, respectively, to achieve an $\mathrm{E} / \mathrm{N}$ ratio of approximately $125 \mathrm{Td}$. The primary ion count ranged between $(2.2-3.6) \times 10^{6}$ with an average of $2.8 \times 10^{6}$. The reagent ions ranged between $(1.07-2.62) \times 10^{5}$ with a mean of $1.69 \times 10^{5}$ which represented $6 \%$ of the primary ion signal. Average normalised counts ranged between 3 (benzene) and 72 [ncps] (methanol) with instrument sensitivities in the range of 4.3 (isoprene)-13.3 (benzene) ncps ppbv ${ }^{-1}$.

A VOC gas standard was not available for on-site calibration of the PTR-MS, hence mixing ratios were calculated using the instrument specific transmission coefficients and reaction times taken from Zhao and Zhang (2004). The transmission coefficients were calculated experimentally under laboratory conditions using a range of gas standards and the method used has been described in detail by Wilkinson (2006). Despite the careful calculation of coefficients, previous studies (de Gouw and Warneke, 2007) have suggested mixing ratios calculated using this approach can have large systematic errors, therefore some systematic bias in mixing ratios cannot be ruled out here. It should be noted that a systematic offset in the VOC mixing ratio due to the instrument background will not affect the measured fluxes.

Additional uncertainties in PTR-MS measurements arise due to the limitations of the mass filter, which can only resolve ion counts with a resolution of one atomic mass unit. Therefore attributing ion counts to individual VOC species can be difficult, especially in the urban environment where numerous emission sources give rise to air masses containing a wide variety of compounds, several of which may have the same integer molecular weight. Interference from other ions at $m / z 33,45,79$ and 93 has been shown to be insignificant in previous studies (de Gouw et al., 2007), but both acetone and propanal have been detected at amu 59. Although this can generate some uncertainty in the measurement of acetone, the signal of acetone is often dominant in ambient air (Kato et al., 2004), therefore ion counts recorded at $m / z 59$ 
were ascribed solely to acetone in the present study. Similarly $m / z, 69$ may be isoprene and/or furan, although the latter is normally present at very low concentrations in ambient air (Christian et al., 2004). Despite this, in the urban atmosphere, contributions from unknown compounds such as alkenes cannot be ruled out and therefore $m / z 69$ was tentatively attributed entirely to isoprene.

\subsection{Flux measurements}

During the campaign, two flux measurement techniques (DEC and vDEC) were employed to measure surface layer fluxes of VOCs from the urban canopy. As both techniques utilised a single PTR-MS instrument to give VOC concentrations, it was not possible to operate the systems simultaneously, and therefore fluxes were measured by the two methods in alternate half hours. A Teflon 3-way solenoid valve (001-0017-900, Parker Hannifin) sat in line and enabled the PTR-MS to switch between the two systems. Flux measurements in each mode were averaged over a $25 \mathrm{~min}$ period and the remaining $5 \mathrm{~min}$ of each half hour were used to scan the entire mass spectrum $(m / z 21-146)$ to give basic ambient concentration information on a wider range of VOCs. This information is to be presented elsewhere. Figure 1 shows a typical PTR-MS operating sequence during $1 \mathrm{~h}$ of measurements and includes the PTR-MS scan cycles for each flux mode.

\subsubsection{Virtual disjunct eddy covariance sampling system (vDEC)}

During the first period of each hour, the 3-way solenoid valve was triggered to enable the PTR-MS to sub-sample directly from the main sample line in a virtual disjunct eddy covariance mode. The quadrupole was set to scan each mass at a rate of $20 \mathrm{~ms}$, allowing sample air to be purged directly into the instrument without the use of an additional sampling system. The inlet for the sample line was mounted a short distance below the sonic anemometer, as vertical displacement has been shown to result in the smallest flux losses (Kristensen et al., 1997). In order to maintain a turbulent flow through the sample line, and thus avoid dampening of the VOC signal, a flow rate of approximately $601 \mathrm{~min}^{-1}$ was used. Upon the completion of each PTR-MS scan cycle, data were exported to a LabVIEW logging program using the Microsoft Windows "dynamic data exchange" (DDE) protocol, which stored the data alongside those from the sonic anemometer.

\subsubsection{Disjunct flux sampling system (DFS)}

A disjunct flux sampling system was deployed on the roof of the building to monitor the VOC fluxes for the second period of each hour. The schematic and operating sequence of the DFS are depicted in Fig. 2. The sampler comprised two one litre stainless steel canisters, which act as intermediate storage reservoirs (ISR) for sampled air. Fast switching high flow conductance valves (Lucifer E121K45) were mounted to the inlet of each canister, enabling the ISR to take a fast grab sample once activated. Each ISR was coiled with heater cable and insulated with aluminium foil to maintain an internal temperature of $40^{\circ} \mathrm{C}$. This, combined with the cylindrical shape of the canisters which reduced relative surface area, helped to minimise loss of VOCs to walls, and minimised condensation and the formation of liquid water, which can remove soluble compounds such as methanol from the gas phase.

Before grab samples of air were taken, each ISR was first evacuated to a pressure of $250 \mathrm{mbar}$. The time taken to evacuate the canister, $12 \mathrm{~s}$, was determined by the efficiency of the pump and proved to be the limiting factor in determining the length of time between sampling. By contrast, the time taken to fully pressurise the ISRs, $0.5 \mathrm{~s}$, proved to be the limiting factor in determining sampling times. This value is more than double that of previous studies (Grabmer et al 2004; Rinne et al., 2000, 2001; Warneke et al., 2002) and is thought to be a consequence of the flow resistance of the sample tube, and the reduced pressure in the $1 / 2^{\prime \prime}$ inlet tube (see below). This considered, the overall effective response time of the DFS setup is about $0.5 \mathrm{~s}$, which is sufficient to resolve turbulent fluctuations of up to $1 \mathrm{~Hz}$. In comparison, the effective response time of the vDEC system, which is limited by the response time of the PTR-MS and not sample integration time, was approximately $1 \mathrm{~s}$. Therefore, despite the shorter dwell time used in vDEC $(20 \mathrm{~ms})$ the effective response time was longer than in DEC, allowing turbulent fluctuations of up to $0.5 \mathrm{~Hz}$ to be resolved. At a measurement height of $95 \mathrm{~m}$ the portion of the total flux carried in the sub $1 \mathrm{~s}$ range is negligible (estimated from Horst, 1997) and therefore no explicit corrections were applied. Simulations, using the sensible heat flux data, indicate that on average $5 \%$ of the heat flux were carried by frequencies between 0.5 and $1 \mathrm{~Hz}$. The effect is discussed below.

Grab samples of air acquired by the DFS were analysed for VOCs using the PTR-MS, which was connected to the DFS via a $4 \mathrm{~m}$ length of $1 / 8^{\prime \prime}$ PFA tubing. The rate at which the PTR-MS draws air from the ISR is important as a vacuum is gradually generated as air is sampled. This back-pressure can affect the pressure in the drift tube, which can lead to small changes in the $\mathrm{E} / \mathrm{N}$ ratio of the instrument. In order to prevent this problem, the flow rate of the PTR-MS was reduced from $300 \mathrm{ml} \mathrm{min}^{-1}$ to $150 \mathrm{ml} \mathrm{min}^{-1}$.

The PTR-MS was housed some distance from the sonic anemometer. Thus the sampling line between ISRs and PTRMS would have been too long for the DFS to be mounted on the anemometer mast. Instead it was located at the base of the tower, with each sample valve connected via a "T-piece" into the $1 / 2^{\prime \prime}$ OD sampling line. This setup had three drawbacks: firstly, the sample line is subject to a pressure drop of approximately 200 mbar, caused by the high flow rates used. Consequently, upon activation of sample valves each ISR could 
Flux measurement sequence

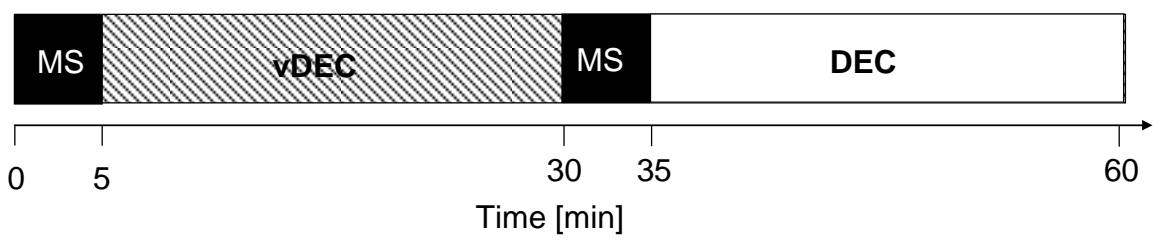

vDEC Duty Cycle

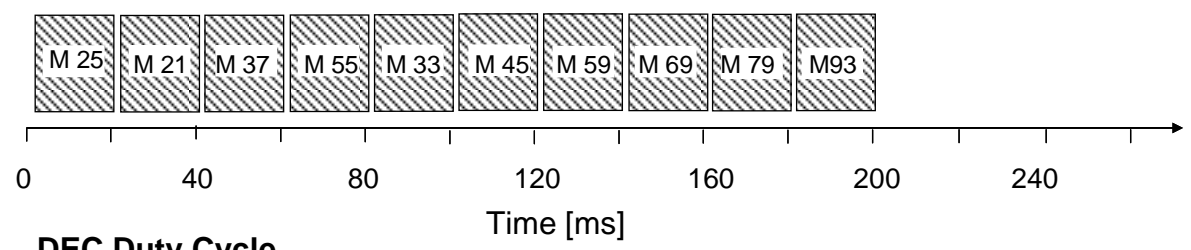

DEC Duty Cycle

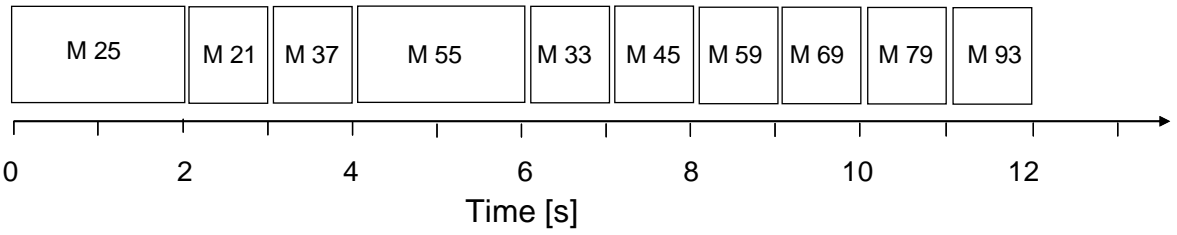

Fig. 1. Representation of the PTR-MS measurement sequence used at Portland Tower. When operating in vDEC mode the scan cycle lasted for a total of $200 \mathrm{~ms}$, whereas in DEC mode dwell times were increased and a 12-s scan cycle was used.

only pressurise to 800 mbar, increasing their effective carryover between samples from $25 \%$ under normal operating conditions (at 1000 mbar) to $\sim 31 \%$. Secondly, air for analysis by the PTR-MS had to travel through an additional $4 \mathrm{~m}$ of $1 / 8^{\prime \prime}$ tubing which may have resulted in the dampening of the VOC signal. Finally, the additional inlet lines results in a time lag between the wind measurement and the filling of the ISR which had to be corrected for, similar to the correction in the vDEC approach. This correction is not required if the DFS can be mounted next to the anemometer.

The sequence of valve switching used to control both the sample and analysis phases of the DFS, which, combined with valve switching, pressure recording, sonic anemometer and PTR-MS data recording, were all coordinated using LabVIEW software (National Instruments - v6.1). The valves were controlled through a multifunction IO card (6071E, National Instruments), which also recorded the analogue signals from the pressure sensors of the ISR (OMEGA, Stamford, Connecticut, PX137-015DV).

\subsubsection{Flux calculations}

In the eddy covariance technique, the flux of an atmospheric scalar is calculated using the covariance between continuous time series of vertical wind speed and scalar concentration at a fixed point in space over a statistically representative time period. Since the data generated by the disjunct flux systems are simply a sub-set of the continuous time series, the flux

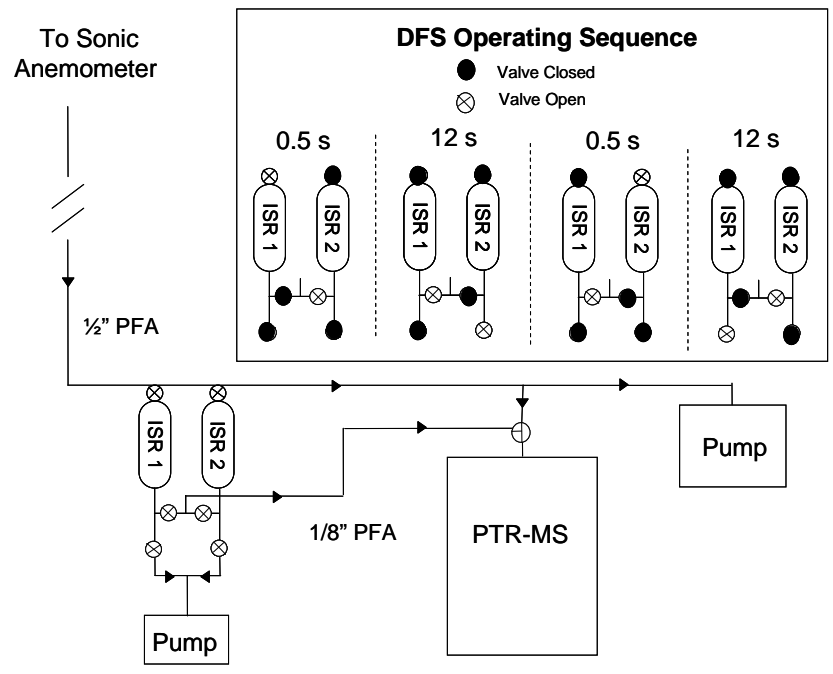

Fig. 2. Schematic of the experimental setup used at Portland tower. The inset diagram shows the operating sequence of solenoid valves which controlled the sample and analysis phase of the disjunct flux sampler (DFS). ISR=Intermediate storage reservoir.

may be calculated in the same way; thus observations of vertical wind velocity $(w)$ were paired with the corresponding 
Table 1. Summary of VOC mixing ratios and flux measurements between 5 and 20 June 2006, in Manchester (UK).

\begin{tabular}{lrrrrrr}
\hline $\begin{array}{l}\text { Concen- } \\
\text { trations }\end{array}$ & Methanol & $\begin{array}{r}\text { Acetal- } \\
\text { dehyde }\end{array}$ & Acetone & Isoprene & Benzene & Toluene \\
[ppb] & $(m / z 33)$ & $\begin{array}{r}\text { (m/z 45) } \\
(m / z 59)\end{array}$ & $(m / z 69)$ & $(m / z 79)$ & $(m / z 93)$ \\
\hline Mean & 3.10 & 1.20 & 1.10 & 0.30 & 0.10 & 0.20 \\
Median & 2.92 & 1.14 & 1.00 & 0.29 & 0.08 & 0.14 \\
Percentiles & & & & & & \\
$\quad-\quad$ 5th & 1.77 & 0.63 & 0.52 & 0.13 & 0.03 & 0.06 \\
$\quad-\quad 95$ th & 5.25 & 1.83 & 1.94 & 0.50 & 0.14 & 0.35 \\
SD & 1.15 & 0.41 & 0.48 & 0.12 & 0.04 & 0.10 \\
Geo SD & 1.40 & 1.40 & 1.50 & 1.60 & - & 1.70 \\
$\mathrm{~N}$ & 354 & 354 & 354 & 353 & 353 & 354 \\
Fluxes & & & & & & \\
[mg m ${ }^{-2} \mathrm{~h}^{-1}$ ] & & & & & & \\
Mean & 0.54 & 0.38 & 0.53 & - & 0.12 & 0.28 \\
Median & 0.49 & 0.39 & 0.51 & - & 0.12 & 0.24 \\
Percentiles & & & & & & \\
$\quad-\quad 5$ th & -0.74 & -0.82 & -0.69 & - & -0.19 & -0.48 \\
$\quad-\quad 95$ th & 1.25 & 1.05 & 1.55 & - & 0.37 & 0.74 \\
SD & 0.71 & 0.68 & 0.66 & - & 0.18 & 0.41 \\
$\mathrm{~N}$ & 200 & 200 & 195 & - & 186 & 200 \\
\hline
\end{tabular}

PTR-MS data $(\chi)$ to give a flux as follows:

$F_{\chi}(\Delta t)=\frac{1}{N} \sum_{i=1}^{N} w^{\prime}\left(i-\Delta t / \Delta t_{w}\right) \chi^{\prime}(i)$

where primes indicate instantaneous fluctuations about the mean vertical wind and VOC concentration measurements (i.e. $w^{\prime}=w-\bar{w}$ ), $\Delta t$ represents the variable lag time that exists between wind and PTR-MS measurements, $\Delta t_{w}$ is the sampling interval of the vertical wind velocity measurements $(0.05 \mathrm{~s})$ and $N$ gives the number of PTR-MS measurements during each $25 \mathrm{~min}$ averaging period (7500 for vDEC and 125 for DEC).

Values of $\Delta t$ were calculated by finding the maximum in covariance function between values of $w^{\prime}$ and $\chi^{\prime}$ within a set time window. The lag time was not constant due to fluctuations in temperature and pressure and the performance of the pump which varied over time. For vDEC measurements the peak was typically found between 10 and 20 seconds whereas DEC lag times were much longer, $40-50 \mathrm{~s}$, due to the cycling delay of the DEC system (12s) and an increased length of sample tubing.

Standard rotations of the coordinate frame were applied to correct for tilting of the sonic anemometer. The vertical rotation angle showed a clear relationship with wind direction, with maximum values of up to $15^{\circ}$. This is similar to other flux measurements in the urban environment (e.g. Nemitz et al., 2002) and suggests that, although the mean airflow at the anemometer is affected by the building, the influence can be compensated by standard rotational corrections.

Calculated fluxes were subject to a post-processing algorithm which filtered and removed data that failed to meet specified quality controls. These included removal of large spikes in vertical wind speed or VOC concentration and the omission of data where the friction velocity $\left(u_{*}\right)$ dropped below $0.15 \mathrm{~m} \mathrm{~s}^{-1}$. This latter QA procedure resulted in the loss of $7 \%$ of the flux data.

In addition, during post-processing of the data, it was found that the inlet pump was occasionally shut down by its thermal trip. The affected time periods were filtered and the spikes removed, affected averaging periods were not included in the final flux analysis. This meant approximately $31 \%$ of measured flux data was deemed unusable and are not included in the analysis here.

\section{Results and discussion}

\subsection{VOC mixing ratios}

Mixing ratios of VOCs measured by the PTR-MS are summarised in Table 1 and the 25 min average values are plotted alongside temperature and wind direction in Fig. 3. The oxygenated compounds, methanol, acetone and acetaldehyde, were the most abundant (methanol 1.3-8 ppbv; acetone 0.34.4 ppbv; acetaldehyde $0.44-3.2 \mathrm{ppbv}$ ). The higher mixing ratios of methanol compared with the other analytes are typical for urban VOC composition measurements and can be attributed to its relatively low photochemical reactivity (Atkinson, 2000) and the numerous anthropogenic/biogenic sources which contribute to its emissions both in and outside of the city (de Gouw et al., 2003). Comparisons of methanol concentrations with previous studies shows the values observed here to be within the lower range of concentrations measured in Barcelona (Filella and Penuelas, 2006) and within the range of values recorded in Innsbruck (Holzinger et al., 2001). The concentrations of the other two oxygenated compounds, acetone and acetaldehyde, both lie within the range of data reported from other major conurbations such as Rome (Possanzini et al., 1996), Los Angeles (Grosjean et al., 1996) and Rio de Janiero (Grosjean et al., 2002).

Concentrations of isoprene ranged between 0.07$0.75 \mathrm{ppbv}$, which is consistent with values obtained from the national air quality monitoring network (http://www.airquality.co.uk/archive/reports/cat13/

0602011042_q3_2005_rat_rep_issue1_v5.pdf) for other UK cities, including Bristol and London. The aromatic compounds, benzene and toluene, were the least abundant of the VOCs measured, ranging between $0.02-0.2$ and $0.03-0.73$ ppbv respectively. These values also compared well with data obtained from the national network (www.airquality.co.uk) automatic monitoring station on Marylebone Road, London although, on average, concentrations from the London site were higher, presumably due to the kerbside location of the sampler, compared with a sampling height of $95 \mathrm{~m}$ for the concentrations reported here.

Linear relationships were observed between the concentrations of each of the measured VOCs, with $R^{2}$ values rang- 


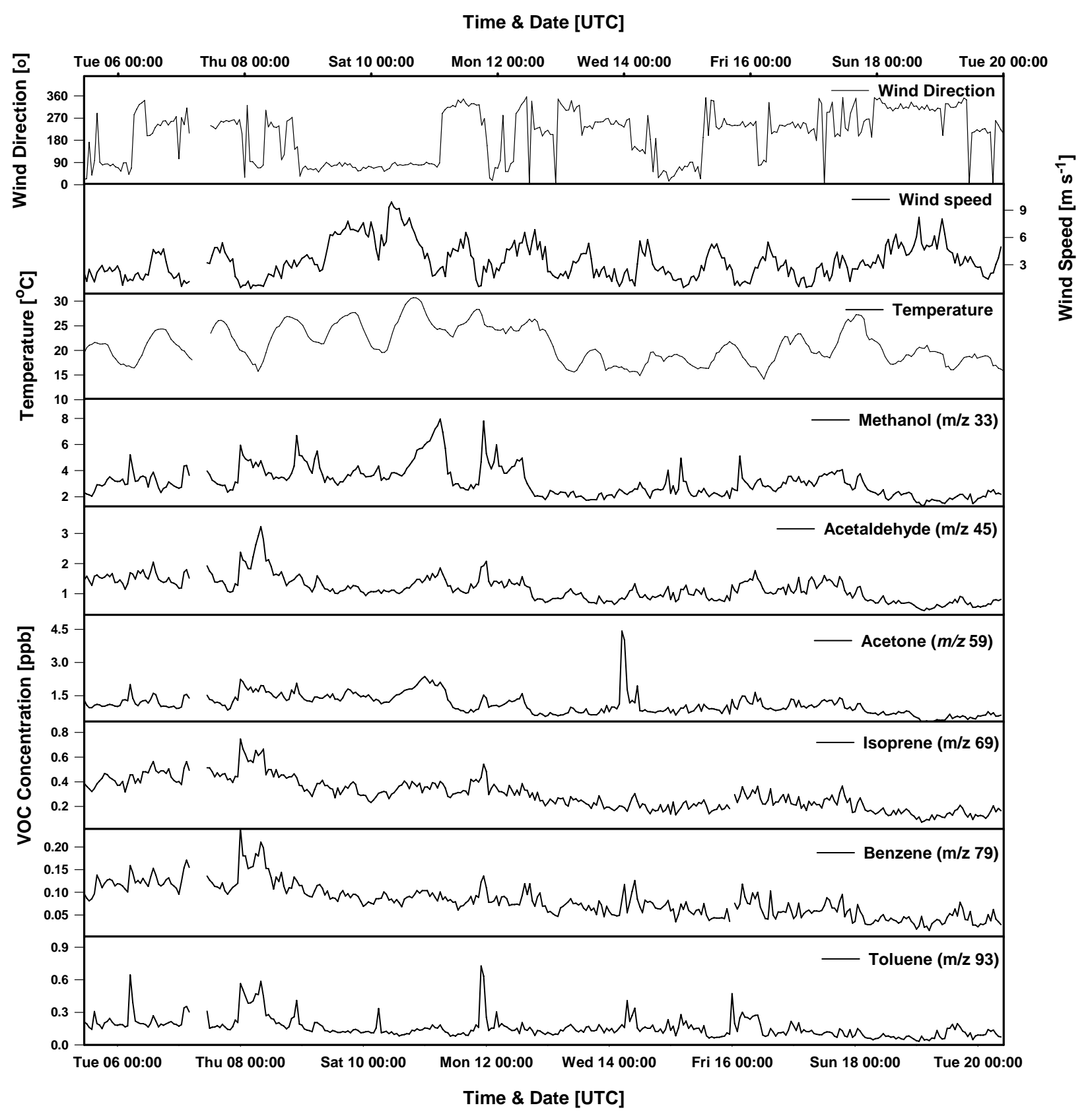

Fig. 3. Plot showing $30 \mathrm{~min}$ average wind direction, wind speed and temperature as recorded by the sonic anemometer and the $25 \mathrm{~min}$ average concentrations of VOCs measured by the PTR-MS between 5 and 20 June.

ing between 0.24 and 0.85 , suggesting some commonality between the sources of emission for each of the compounds.

Clear day-night trends in mixing ratios were not always apparent, with maxima occasionally observed at night time (Thursday 8th, Saturday 11th), whereas on other days (Saturday 17th-Tuesday 20th) they tended to peak during the late afternoon. Spikes were frequently observed in the concentration of methanol during the early morning. This often corresponded to lower temperatures and low wind speed in the early morning and is consistent with previous urban VOC studies which have attributed this trend to condensation processes (Fiella and Penuelas, 2006). The nocturnal increase in concentrations for the other compounds is unclear, but is likely a combination of small night-time emissions accumulating in the shallow nocturnal boundary layer, the dynamics of which differed between the different nights. These emissions may include combustion and fugitive emissions from industrial activity outside the flux footprint, on the outskirts of the city. 

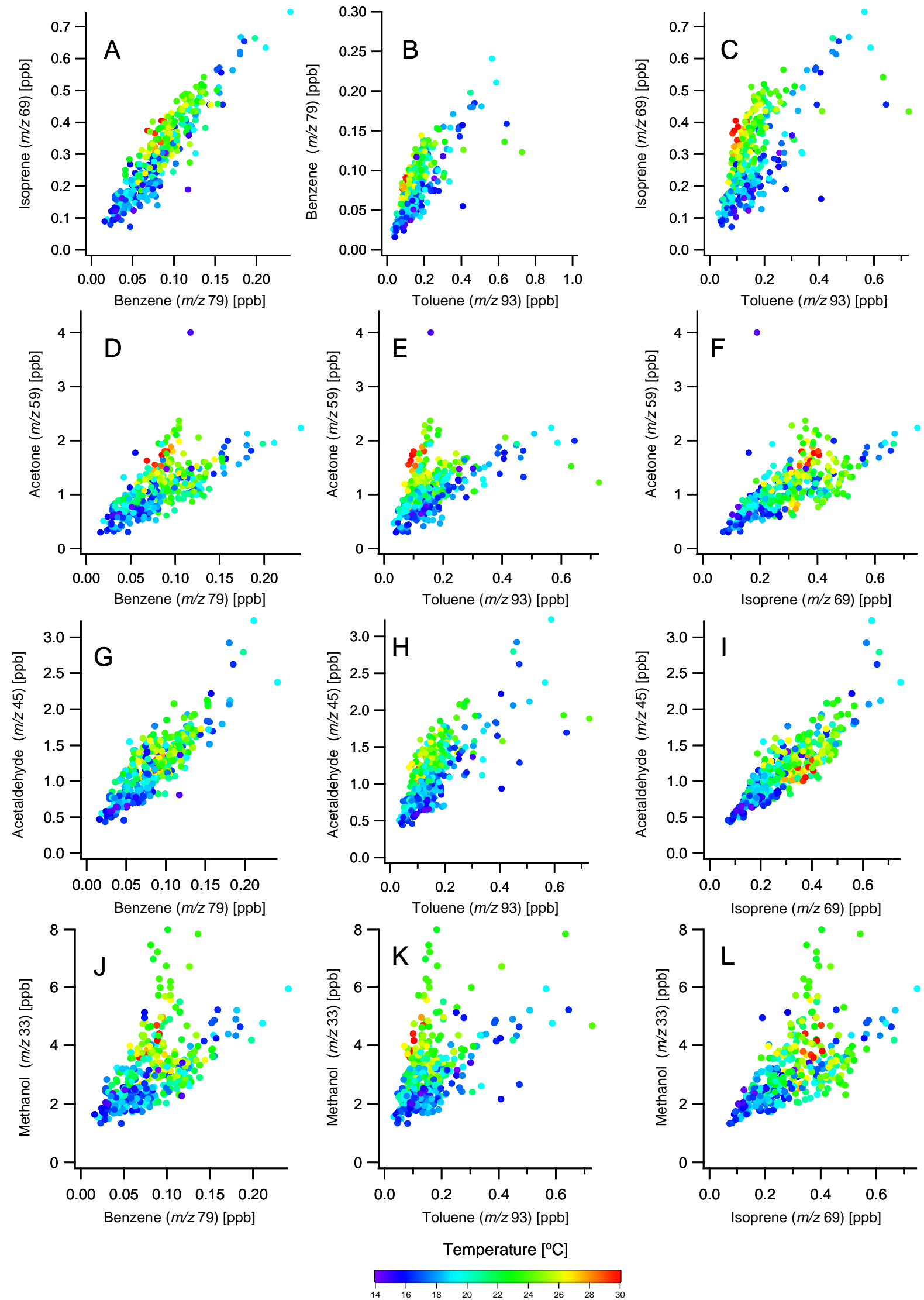

Fig. 4. Scatter plots of VOC concentrations measured at Portland Tower, Manchester. Colour bar corresponds to ambient air temperature at the time of sampling. 
Additional spikes in VOC concentrations can be observed in Fig. 3. While some of these can be ascribed to changes in wind direction, such as those observed in $\mathrm{m} / z 59$ on the 14th, others, as seen in $m / z 93$ on the 16th cannot.

Figure 4 shows scatter plots of VOC mixing ratios for different pairs of compounds measured during the vDEC mode between 5 and 20 June. These plots are useful for the interpretation and source apportionment of data. For example, strong linear relationships, as seen in panel A or I, may suggest a similar source contributing to the emission of the two compounds, whereas in panel $\mathrm{K}$, where a bimodal (or even trimodal) distribution is evident, it is possible that there are two (or three) separate sources contributing to the observed VOC concentrations. Further information can be obtained from these plots by differentiating data points by a third variable, in this case temperature as reflected in the colour coding, which in some instances (e.g. panel E) can reveal what appears to be a temperature dependency in the measured concentration of the VOC. To help with the further interpretation of the data shown in Fig. 4, Table 2 lists some of the known anthropogenic, biogenic and chemical sources of the measured compounds and also includes atmospheric lifetimes with respect to $\mathrm{OH}, \mathrm{NO}_{3}, \mathrm{O}_{3}$ and photolysis.

Figure 4, panel A, shows the correlation between isoprene $(\mathrm{m} / \mathrm{z} 69)$ and benzene $(\mathrm{m} / \mathrm{z}$ 79). Both these compounds are known constituents of petrol fuel (Borbon et al., 2001), and consequently they are emitted to the atmosphere by the same two anthropogenic sources: direct emissions in vehicle exhausts and evaporative emissions from petroleum products, hence the strong linear relationship $\left(R^{2}=0.87 ; p<0.0001\right)$ observed between the two compounds during this study. This also suggests that biogenic sources do not make a significant contribution to mixing ratios at this site.

Toluene was the least volatile of the compounds measured during this study and the ratios of its concentration against those of benzene, isoprene, acetone, acetaldehyde and methanol did not vary with temperature (Fig. 4, panels B, C, E, H and K, respectively). However, in each of these plots, bimodal distributions were observed and each of the aforementioned compounds appeared to demonstrate some degree of temperature dependency with respect to toluene, although this varied between compounds. Acetone appearing to be highly temperature dependent, whereas benzene showed only a slight variation with temperature.

Benzene and toluene are both present in primary vehicle exhaust emissions (Jobson et al., 2005), and have differing atmospheric lifetimes with respect to the $\mathrm{OH}$ radical and consequently analysis of the benzene to toluene ratio $(\mathrm{B} / \mathrm{T})$ provides a tool to gauge the photochemical age of an air mass (Warneke et al., 2001). Previous studies have shown the B/T ratio in primary exhaust emissions to typically lie in the range of 0.41-0.83 (Heeb et al., 2000), but this ratio increases as toluene reacts with the $\mathrm{OH}$ radical faster than benzene and is preferentially removed over time in the atmosphere. In the present study the average $\mathrm{B} / \mathrm{T}$ ratio was approximately

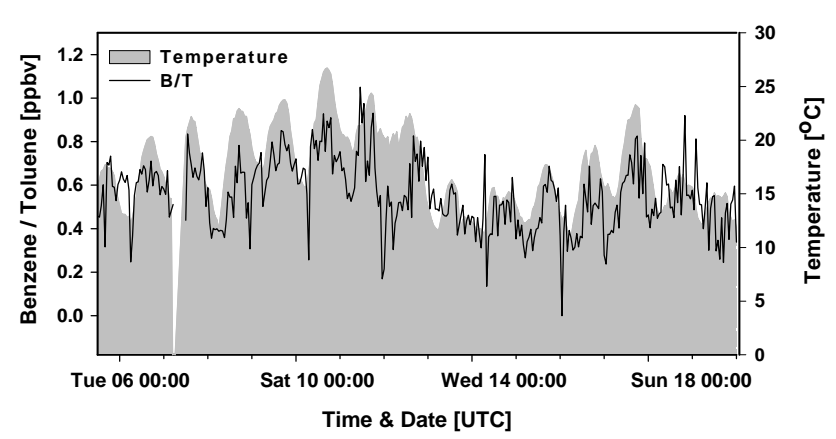

Fig. 5. The ratio of benzene to toluene (solid line) followed the average temperature (greyed area), suggesting an increase in the removal rate of toluene due to increased levels of $\mathrm{OH}$ at higher temperatures.

0.57 (Fig. 5), suggesting the observed concentrations were typically originating from sources close to the measurement site. However, during the period of elevated temperatures (9-12 June), the ratio increased to an average 0.67 , which suggests that the removal rate of toluene increased due to higher concentrations of the $\mathrm{OH}$ radical corresponding to the increase in temperature.

Acetone $(m / z 59)$ appeared to show the greatest degree of temperature dependence of all the measured VOCs. Like acetaldehyde, acetone can be formed in the atmosphere as a product of the photooxidation of other hydrocarbons, including propane, isobutene and isopentane (Singh and Zimmerman, 1992). These are primary vehicle exhaust pollutants (Hwa, 2002; Chiang et al., 2007); however, the atmospheric lifetime of each is typically on the order of tens of days, therefore temperature-dependent photooxidation is unlikely to be a major source of acetone within the city. Both acetone and acetaldehyde are themselves found in vehicle exhaust emissions (Sigsby et al., 1987; Caplain et al., 2006), which accounts for the close relationship observed with benzene concentrations. Again, the apparent temperature dependency of these compounds, seen in Fig. 4, panels D and G, could be related to their high volatilities, leading to fugitive evaporative emissions at higher temperatures. Although acetaldehyde is more volatile than acetone, and therefore should demonstrate the greatest tendency to evaporate at higher temperatures, acetone has a wider distribution of potential sources as it is not only found in petrol but also in a wide range of solvents and cleaning fluids (Table 2). Furthermore, the shorter atmospheric lifetime of acetaldehyde, which is removed by oxidation and photolysis (both likely to be strongly correlated with temperature), may also contribute to the less prominent temperature dependency.

\subsection{VOC fluxes}

Averaged diurnal fluxes for the period 5-20 June 2006, as measured by both the DEC and vDEC techniques, are shown in Fig. 6. Data included in the averages were selected from 
Table 2. List of biogenic, anthropogenic and secondary atmospheric chemistry sources of VOCs and atmospheric lifetimes with respect to $\mathrm{OH}, \mathrm{NO}_{3}, \mathrm{O}_{3}$ and photolysis. The temperature dependency (TD) of each source is listed, where 5 stars represent a very high dependency and 1 star a very low dependency.

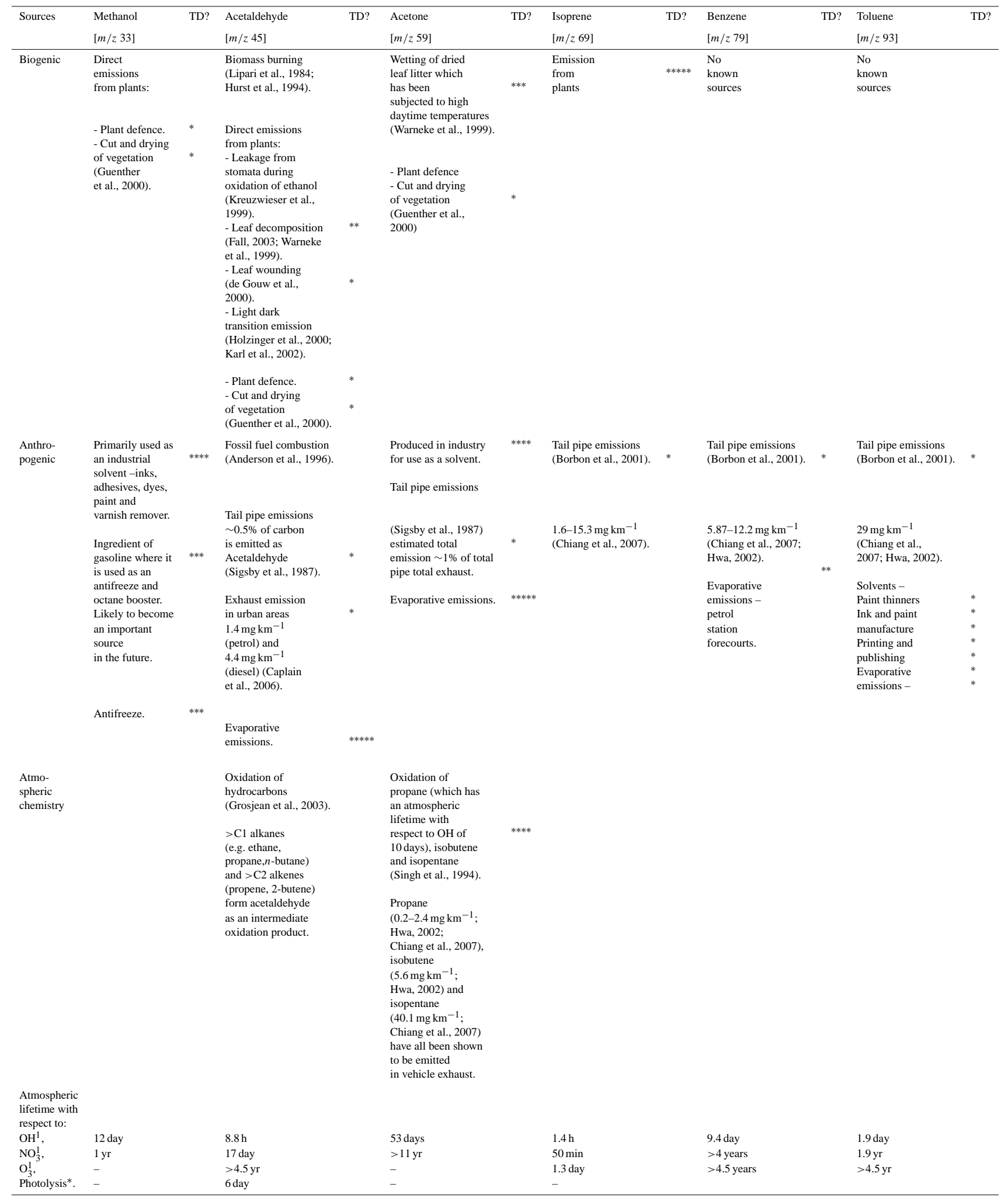

1 Atmospheric lifetimes of VOCs are taken from Atkinson (2000). 

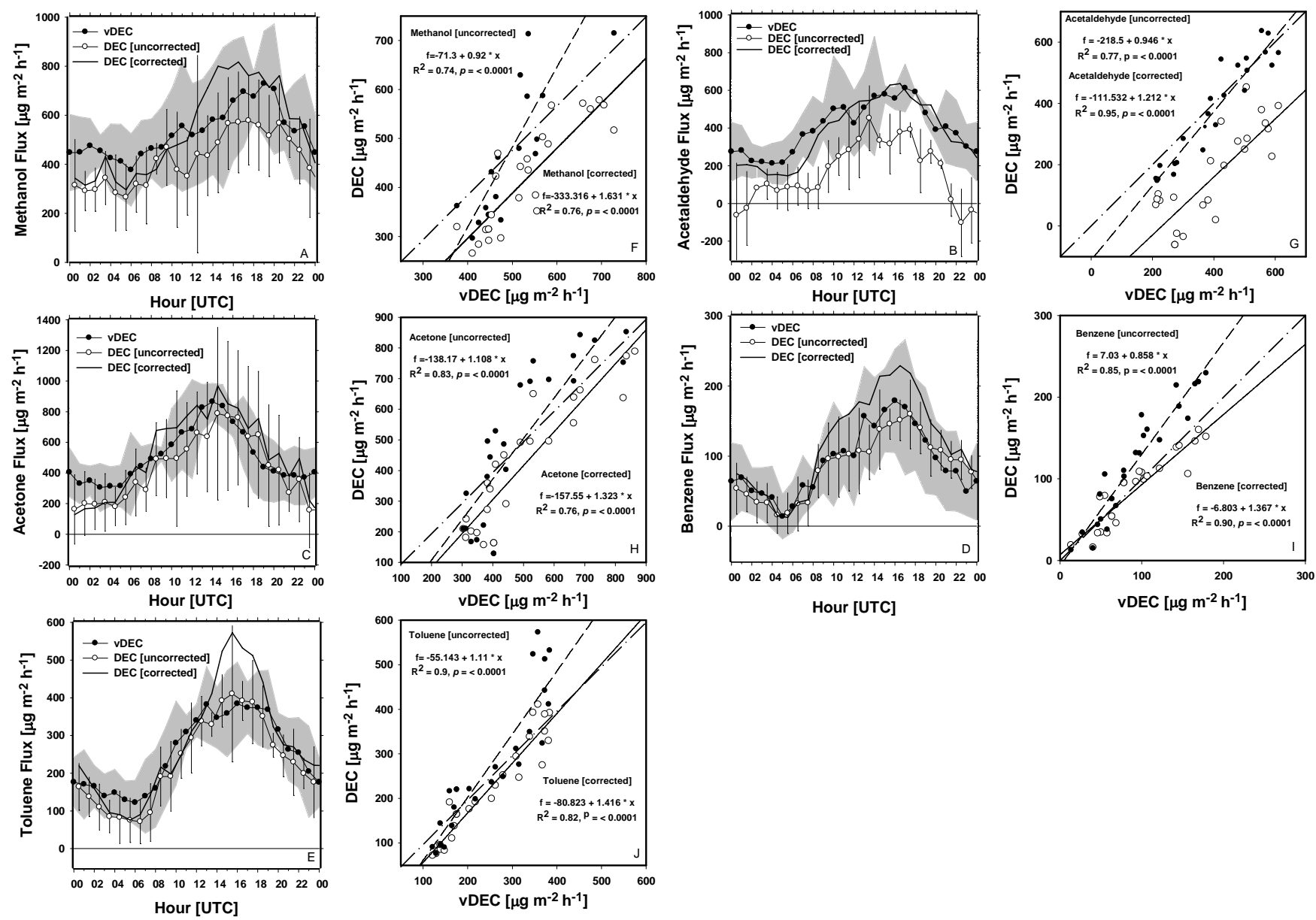

Fig. 6. Panels A, B, C, D and $\mathbf{E}$ show the average daily fluxes for methanol, acetone, benzene and toluene measured by the DEC and vDEC techniques. The error bars represent 1 standard error of the averages of the vDEC flux. Panels $\mathbf{F}, \mathbf{G}, \mathbf{H}$ and $\mathbf{I}$ show the corresponding regression plots for both corrected (closed circles, dashed line) and uncorrected DEC fluxes (open circles, solid line), where the correction takes into account the carry over between subsequent samples in the ISRs.

time periods where measurements from both systems were available. Despite some variability between the two systems, both techniques show VOC fluxes to have a clear diurnal trend, with fluxes at their largest in the mid to late afternoon and lowest in the early hours of the morning. On average, fluxes were positive for most of the day, indicating the city to be acting as a net source of VOC to the atmosphere, although deposition was observed for short periods at night. On average, fluxes of methanol were the largest $\left(0.54 \mathrm{mg} \mathrm{m}^{-2} \mathrm{~h}^{-1}\right)$, followed by acetone, $\left(0.53 \mathrm{mg} \mathrm{m}^{-2} \mathrm{~h}^{-1}\right)$ and acetaldehyde, $\left(0.38 \mathrm{mg} \mathrm{m}^{-2} \mathrm{~h}^{-1}\right)$, whereas fluxes of the aromatic compounds benzene and toluene were lower $\left(0.12 \mathrm{mg} \mathrm{m}^{-2} \mathrm{~h}^{-1}\right.$ and $0.28 \mathrm{mg} \mathrm{m}^{-2} \mathrm{~h}^{-1}$, respectively). Isoprene fluxes were omitted from the final analysis, as significant differences were observed between the two techniques, indicating a possible source of contamination in one or other of the systems.
Panel A, Fig. 6, shows the average daily flux of methanol. Typically, fluxes of methanol started to increase at around 06:00, rising steadily until a broad evening maximum was reached between 16:00 and 21:00 GMT. At this time fluxes dropped off sharply before levelling and reaching a minimum during the early morning. Acetaldehyde fluxes (panel B) also had a broad daytime peak, but in contrast to methanol, fluxes tended to be larger in the late morning and early afternoon.

The remaining three compounds each shared a similar trend that saw emissions rise between 05:00 and 06:00, reaching a broad peak between 14:00 and 19:00 GMT. This afternoon maximum was reflected in measurements of traffic density (Fig. 7) taken on Oxford Road, a busy street adjacent to Portland Street. Measurements from this location provide a good proxy for the relative change of the diurnal traffic pattern in the area. They also indicate a clear morning rush hour peak which is not reflected in the observed fluxes. The 


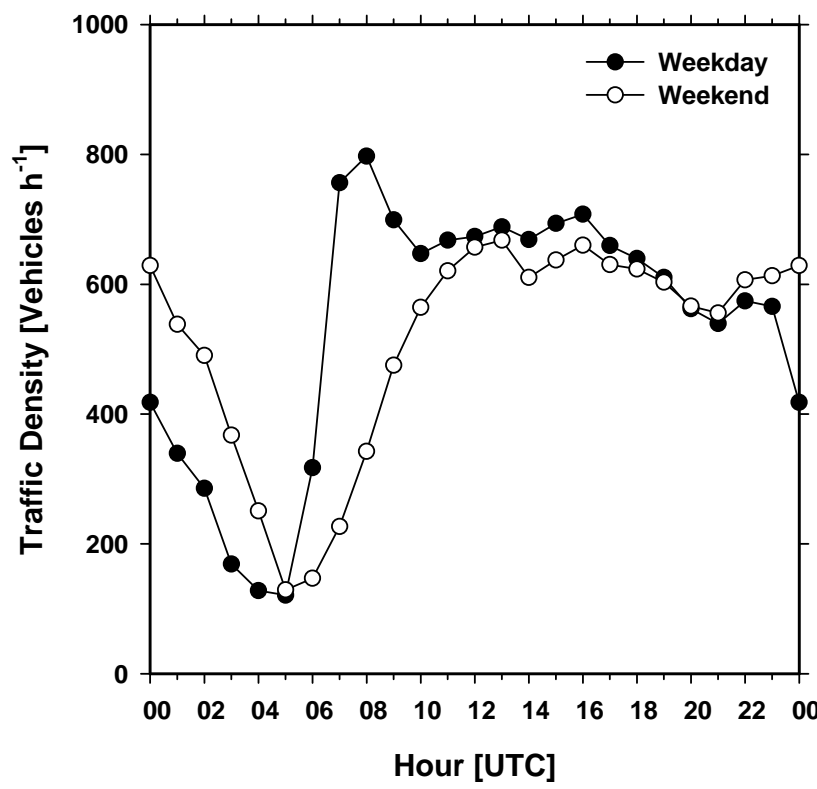

Fig. 7. Traffic density measured on Oxford Road (street adjacent to Portland Street). This provides a good proxy for the relative change of traffic activity in the local area.

absence of this peak in the flux measurements is not unique to this site (Nemitz et al., 2002) and is thought to relate to a number of factors: firstly, flux measurements represent the average surface exchange occurring over a large area, thus rush hour trends which may be more apparent on some roads (e.g. bus routes such as Oxford road) than others, become smeared. Secondly, during the day there is more stationary traffic, due to loading/unloading and congestion. Thirdly, for measurements of VOCs which might partially be under temperature control, fugitive emission may become an important source at midday when temperatures are warmest and consequently any rush hour trend within the data becomes smoothed. Furthermore the use of products (e.g. cleaning products, solvents) is not likely to be linked to traffic counts. Finally, the fluxes presented here are an average of both weekday and weekend fluxes, which, as shown by Fig. 7, may also dampen any rush hour trend in the data.

Regardless of these factors it is still possible that some of the flux is missed by the measurement systems, as during stable night-time conditions and on calm mornings/evenings the measurement site may become decoupled from the street canyon below. Although this may result in damping of some temporal features, the effect is somewhat reduced through nocturnal heat output from the city and the relatively windy location and therefore the average daily fluxes presented here should provide a robust estimate of the total exchange occurring throughout the day.

The similarities between traffic counts and VOC fluxes suggest vehicle emissions to be the dominant source for most VOCs, but not all. Methanol and acetaldehyde emis- sions showed some similarities with traffic density but were broader over the day, consistent with a large contribution from fugitive sources that are coupled to a combination of temperature and non-traffic anthropogenic activity such as solvent use.

In order to compare data from the two flux techniques, which did not measure simultaneously, the average daily fluxes were used, thus avoiding uncertainties associated with a changing atmosphere. Despite the indirect nature of the comparison, the two flux measurement systems showed good agreement, with measured fluxes falling within the range of the standard error $(\sigma / \sqrt{ } \mathrm{N})$ of hourly fluxes. The highest observed correlations between the DEC and vDEC techniques were observed in the fluxes of toluene and benzene, which had $R^{2}$ values of $0.9(p<0.0001 ; \mathrm{N}=24)$ and 0.85 $(p<0.0001)$, respectively. Acetone $\left(R^{2}=0.83 p<0.0001\right)$ and acetaldehyde $\left(R^{2}=0.77 p<0.0001\right)$ also compared well, as did methanol $\left(R^{2}=0.74 p<0.0001\right)$.

The regression plots that accompany Fig. 6 clearly show an offset between the two techniques, with the vDEC flux measurements consistently higher than those made by DEC. The offset was highest for acetaldehyde $(46 \%)$ and lowest for benzene $(6 \%)$ with an average deviation of $20 \%$. Part of this offset may relate to the tendency of the VOC to adsorb to the surfaces of the DFS, meaning the signal of the "stickier" compounds such as methanol is dampened. The main cause however, is thought to relate to the carry-over of air from one DEC sample to the next, caused by the incomplete evacuation of the canister. The carry-over for our system was much larger than that reported in previous studies (Rinne et al., 2001) and therefore an alternative data analysis was carried out, incorporating the following correction for carry-over:

$\chi_{\text {corr }}=\frac{\left(\chi \times p_{1}-\chi_{\text {old }} \times p_{2}\right)}{\left(p_{1}-p_{2}\right)}$.

Here $\chi$ is the VOC concentration within the ISR, $\chi_{\text {old }}$ is the previous concentration of the same ISR, $p_{1}$ is the ISR pressure when full and $p_{2}$ is the ISR pressure after evacuation. The correction increases the amplitude of the PTR-MS data and consequently gives larger flux values, as can be seen in Fig. 6. After the correction was applied the average offset between the two systems was reduced to less than 7\%. Despite this correction, $\mathrm{DEC}_{\text {corr }}$ values remained lower than vDEC fluxes at night-time. This is thought to relate to the very short dwell times chosen for the vDEC method, which can result in limited counting statistics.

Counting statistics cause uncertainty in the flux and the error is inversely proportional to $N^{0.5}$, where $N$ is the total number of ion counts during a ( $25 \mathrm{~min}$ ) flux averaging period (Fairall, 1984). $N$ remains similar, independent of whether a concentration is measured frequently with a short dwell time, or less often with a longer dwell time, except for the increased relative dead time associated with switching between $\mathrm{m} / \mathrm{z}$ more rapidly. However, reducing the error associated 
with individual count rates on the raw DEC and vDEC data points is important as it can impact upon the cross-correlation function used to calculate $\Delta t$ and may thus affect the overall precision of the flux measurement. When the random error is high, the cross-correlation becomes noisier and more difficult to interpret, reducing the measurement precision. By looking for the time lag that maximises the cross correlation, fluxes may be systematically biased towards extreme values, which would be more important the noisier the time-series and the smaller the flux (i.e. during night-time). Calculating the flux limit of detection by taking the standard deviation of the covariance function at distances far from the true lag would help to eliminate such periods in the future. It should be noted that, where a constant time-lag can be used, a systematic bias should not occur.

During the daytime, corrected DEC fluxes were larger than vDEC fluxes. Some of this difference can be explained by the faster response time of the DEC system, which could resolve turbulent fluctuations of up to $1 \mathrm{~Hz}$ as opposed to $0.5 \mathrm{~Hz}$ for the vDEC system. Analysis of the sensible heat flux, which we assume to show identical frequency behaviour as the measured VOC, demonstrated that approximately $5 \%$ of the flux was carried in this frequency range.

The uncertainty of flux estimates due to the disjunct sampling protocol was estimated for each system using the approach of Lenschow et al. (1994). Integral time scales $\left(l_{w s}\right)$ ranged between 10-20 s, our averaging period $(T)$ was $1500 \mathrm{~s}$ and our sampling intervals $(\Delta x)$ were $\sim 0.2 \mathrm{~s}$ and $12 \mathrm{~s}$ respectively for the vDEC and DEC techniques. Sampling errors were found to be $<1 \%$ for the vDEC technique and between 6 and $13 \%$ for the DEC mode. These errors are comparably small when considering uncertainties associated with geophysical variability. Errors associated with both unstable and neutral conditions were calculated following the method of Wesley and Hart (1985) and were found to be $47 \%$ and $61 \%$, respectively.

\subsection{Comparison of measured VOC fluxes with NAEI estimates}

Measured VOC fluxes were up-scaled and compared against the most recent (2006) emission estimate for Manchester taken from the UK National Atmospheric Emission Inventory (http://www.naei.org.uk/datachunk.php? $f_{-}$datachunk_id=174). The flux estimates from the $D C_{\text {corr }}$ system were used for the comparison as they did not suffer from the attenuation of high frequency flux contributions. In order to compare the up-scaled fluxes with the inventory it was first necessary to calculate the approximate flux foot print (surface area contributing to the flux) so that the appropriate NAEI grid(s) could be selected for comparison.

Footprints were calculated using a simple parameterisation model developed by Kljun et al. (2004) which was run using typical urban meteorology to give footprints under stable, neutral and convectively unstable atmospheric condi- tions. This model is designed for dynamically homogenous terrain, therefore its application to the urban environment is not ideal; however there are few if any operational footprint models designed for this type of environment. Therefore the flux footprints obtained are treated as a first-order estimate only. The following parameters were used in the model: standard deviation of vertical wind velocity $\sigma_{w}=0.3 \mathrm{~m} \mathrm{~s}^{-1}$; friction velocity $u *=0.3 \mathrm{~m} \mathrm{~s}^{-1}$ (average measurement period); measurement height $z_{m}=95 \mathrm{~m}$; roughness length $z_{0}=1.5 \mathrm{~m}$ (estimated as $1 / 10$ th of the average building height, $15 \mathrm{~m}$ ); and boundary layer height $h=2000 \mathrm{~m}$. The results are shown in Fig. 8 and list the distance at which the maximum contribution to the flux can be expected $\left(X_{\max }\right)$ and the distance which $80 \%$ of the flux is contained $\left(X_{r}\right)$. A circular flux footprint (radius $=X_{r}$ ) was then superimposed over a map of NAEI grid squares and the entrained grids averaged using a weighting factor to account for the measured wind direction during the measurement period.

In order to calculate an emission estimate for the flux footprint using these data, it was assumed that the observed average fluxes were representative of VOC emission rates occurring throughout the year (although the emission rates are likely to show some seasonality, with increased vehicle use during the winter months causing higher direct emissions; this may be balanced by increased fugitive emissions in the summer months). Therefore the measured average total daily flux of benzene for example $\left(2.87 \mathrm{mg} \mathrm{m}^{-2} \mathrm{~d}^{-1}\right.$ $\left.\left(\mathrm{DEC}_{\text {corr }}\right)\right)$ was extrapolated to give an annual emission estimate of $1.0 \mathrm{t} \mathrm{km}^{-2} \mathrm{yr}^{-1}$. This value is 1.5 times greater than that predicted by the NAEI $\left(0.69 \mathrm{t} \mathrm{km}^{-2} \mathrm{yr}^{-1}\right)$ for the same flux footprint during 2006. However, the NAEI estimate falls inside the overall error bounds of the measurement (Fig. 9). Fluxes of toluene compared similarly, with a 1.5 times difference between measurements and inventory. In contrast, fluxes of the oxygenated compounds methanol $(\times 3.6)$, acetaldehyde $(\times 6.3)$ and acetone $(\times 4.7)$ were considerably larger than the emission inventory. This outcome suggests the NAEI is accurately characterising the sources of the aromatic compounds, whose emission is dominated by a single source, in this case road transport. Yet, for the oxygenated VOCs, such as methanol or acetaldehyde, whose emissions may be dominated by numerous diffuse sources, it performs less well. In such instances direct "top-down" flux measurements may provide a more robust approach.

Published VOC fluxes from the urban environment are limited, but fluxes have been measured above Mexico City using a vDEC approach as part of the Mexico City Metropolitan Area 2003 field campaign. Average fluxes of methanol $\left(1.0 \mathrm{mg} \mathrm{m}^{-2} \mathrm{~h}^{-1}\right)$, toluene $\left(0.83 \mathrm{mg} \mathrm{m}^{-2} \mathrm{~h}^{-1}\right)$ and acetone $\left(0.39 \mathrm{mg} \mathrm{m}^{-2} \mathrm{~h}^{-1}\right)$ were found to be up to three times higher than those observed in Manchester (Velasco et al., 2005). This is unsurprising given the much older vehicle fleet, less dominance of catalytic converters and poorer fuel quality in Mexico City, where vehicle emissions are not regulated by the Geneva (UN ECE, 1991) and Gothenburg 


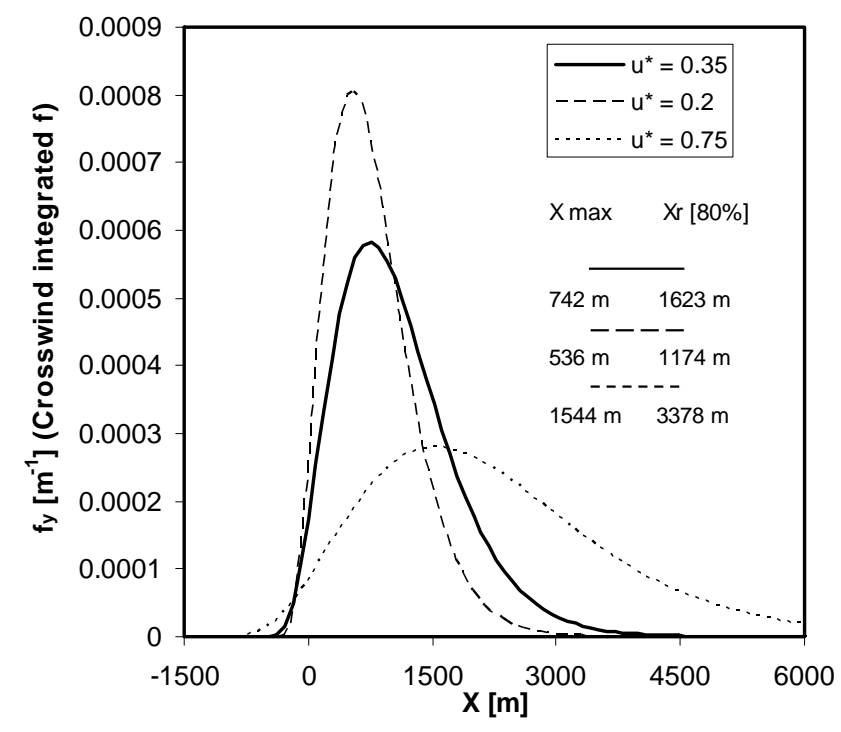

Fig. 8. Predicted one-dimensional flux footprint from Portland Tower, Manchester, where the solid, dashed and dotted lines represent the predicted footprint for $\mathrm{u}^{*}$ values of 0.2 (minimum observed), 0.35 (average for campaign) and $0.75 \mathrm{~m} \mathrm{~s}^{-1}$ (maximum observed).

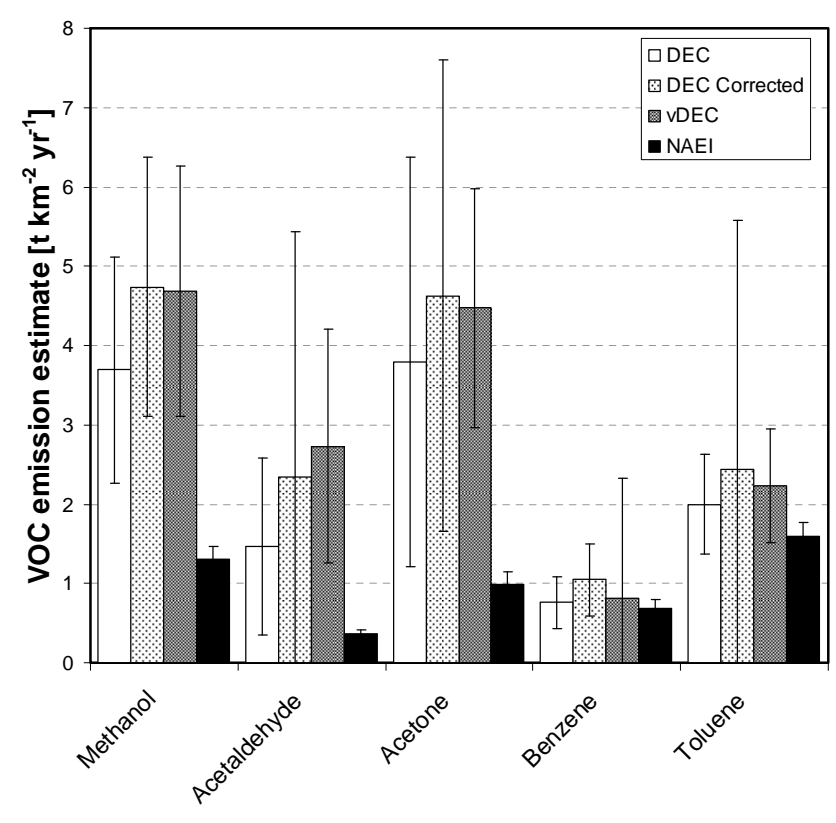

Fig. 9. Emission estimates for Manchester city centre based on up-scaled flux measurements. The emission estimate for benzene

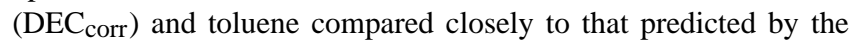
national atmospheric emission inventory. Error bars show the uncertainty of the emission estimate based on the standard error of the flux averages.
(UN ECE, 1999) multi-pollutant protocols as is the case in the UK. By comparison, recent measurements of VOC fluxes by REA over Houston, Texas, (Park et al., 2008) derived fluxes in the range -0.36 to $3.1 \mathrm{mg} \mathrm{m}^{-2} \mathrm{~h}^{-1}$ for benzene and -0.47 to $5.04 \mathrm{mg} \mathrm{m}^{-2} \mathrm{~h}^{-1}$ for toluene.

\section{Conclusions}

In the past the virtual and disjunct eddy covariance techniques have been successfully applied to give flux information from a range of vegetation canopies. In the present study we have shown that these techniques can be extended to the urban environment provided a measurement site with suitable elevation above street level can be found. We have also demonstrated the effectiveness and limitations of each approach. The vDEC technique is thought to be more suited for urban flux work due to its relative simplicity, although longer dwell times are needed to avoid errors associated with limited counting statistics.

Emission estimates derived from flux data demonstrate the potential of using VOC flux measurements in determining emission estimates on a city wide scale. Although emission estimates obtained in this study are based on a "snap shot" of the total annual emission, they demonstrate the potential of the technique, which, if deployed on a longer time scale, such as a year, could give very detailed information on urban-scale emissions, including both spatial and, more importantly, temporal trends, which are currently not accounted for in the NAEI emission estimates.

Acknowledgements. We thank Bruntwood Estates Ltd for allowing access to Portland Tower and for the cooperation and support of their staff. The work was funded by the UK Natural Environmental Research Council through the "CityFlux" grant and an NCAS studentship and by the ESF VOCBAS programme. We thank Ian Longley (Manchester University) who was responsible for the organisation and logistics of the campaign, Gavin Phillips (CEH Edinburgh) for his help transporting the instrumentation and Malcolm Possell (Lancaster University) for helpful discussion.

Edited by: A. B. Guenther

\section{References}

Ammann, C., Brunner, A., Spirig, C., and Neftel, A.: Technical note: Water vapour concentration and flux measurements with PTR-MS, Atmos. Chem. Phys., 6, 4643-4651, 2006, http://www.atmos-chem-phys.net/6/4643/2006/.

Anderson, L. G., Lanning, J. A., Barrell, R., Miyagishima, J., Jones, R. H., and Wolfe, P.: Sources and sinks of formaldehyde and acetaldehyde: An analysis of Denver's ambient concentration data, Atmos. Environ., 30, 2113-2123, 1996.

Atkinson, R.: Atmospheric chemistry of $\mathrm{VOC}$ and $\mathrm{NO}_{\mathrm{x}}$, Atmos. Environ., 34, 2063-2101, 2000. 
Aubinet, M., Chermanne, B., Vandenhaute, M., Longdoz, B., Yernaux, M., and Laitat, E.: Long term carbon dioxide exchange above a mixed forest in the Belgian Ardennes, Agr. Forest Meteorol., 108, 293-315, 2001.

Borbon, A., Fontaine, H., Veillerot, M., Locoge, N., Galloo, J. C., and Guillermo, R.: An investigation into the traffic-related fraction of isoprene at an urban location, Atmos. Environ., 35, 3749 3760, 2001.

Bowling, D. R., Turnipseed, A. A., Delany, A. C., Baldocchi, D. D., Greenberg, J. P., and Monson, R. K.: The use of relaxed eddy accumulation to measure biosphere-atmosphere exchange of isoprene and of other biological trace gases, Oecologia, 116, 306-315, 1998

Brunner, A., Ammann, C., Neftel, A., and Spirig, C.: Methanol exchange between grassland and the atmosphere, Biogeosciences, 4, 395-410, 2007, http://www.biogeosciences.net/4/395/2007/.

Businger, J. A. and Oncley, S. P.: Flux measurement with conditional sampling, J. Atmos. Ocean. Tech., 7, 349-352, 1990.

Caplain, I., Cazier, F., Nouali, H., Mercier, A., Dechaux, J. C., Nollet, V., Journard, R., Andre, J. M., and Vidon, R.: Emissions of unregulated pollutants from European gasoline and diesel passenger cars, Atmos. Environ., 40, 5954-5966, 2006.

Chiang, H. L., Hwu, C. S., Chen, S. Y., Wu, M. C., Ma, S. Y., and Huang, Y. S.: Emission factors and characteristics of criteria pollutants and volatile organic compounds (VOCs) in a freeway tunnel study, Sci. Total Environ., 381, 200-211, 2007.

Christian, T. J., Kleiss, B., Yokelson, R. J., Holzinger, R., Crutzen, P. J., Hao, W. M., Shirai, T., and Blake, D. R.: Comprehensive laboratory measurements of biomass-burning emissions: 2. First intercomparison of open-path FTIR, PTR-MS, and GC-MS/FID/ECD, J. Geophys. Res.-Atmos., 109, D02311, doi:10.1029/2003JD003874, 2004.

Ciccioli, P., Brancaleoni, E., Frattoni, M., Marta, S., Brachetti, A., Vitullo, M., Tirone, G., and Valentini, R.: Relaxed eddy accumulation, a new technique for measuring emission and deposition fluxes of volatile organic compounds by capillary gas chromatography and mass spectrometry, J. Chromatogr. A, 985, 283-296, 2003.

de Gouw, J. and Warneke, C.: Measurements of volatile organic compounds in the Earth's atmosphere using proton-transferreaction mass spectrometry, Mass Spectrom. Rev., 26, 223-257, 2007.

de Gouw, J., Warneke, C., Karl, T., Eerdekens, G., van der Veen, C., and Fall, R.: Sensitivity and specificity of atmospheric trace gas detection by proton-transfer-reaction mass spectrometry, Int. J. Mass Spectrom., 223, 365-382, 2003.

de Gouw, J. A., Howard, C. J., Custer, T. G., Baker, B. M., and Fall, R.: Proton-transfer chemical-ionization mass spectrometry allows real-time analysis of volatile organic compounds released from cutting and drying of crops, Environ. Sci. Technol., 34, 2640-2648, 2000.

Dollard, G. J., Dumitrean, P., Telling, S., Dixon, J., and Derwent, R. G.: Observed trends in ambient concentrations of C-2-C-8 hydrocarbons in the United Kingdom over the period from 1993 to 2004, Atmos. Environ., 41, 2559-2569, 2007.

Dorsey, J. R., Nemitz, E., Gallagher, M. W., Fowler, D., Williams, P. I., Bower, K. N., and Beswick, K. M.: Direct measurements and parameterisation of aerosol flux, concentration and emission velocity above a city, Atmos. Environ., 36, 791-800, 2002.

Fairall, C. W.: Interpretation of eddy-correlation measurements of particulate deposition and aerosol flux, Atmos. Environ., 18, 1329-1337, 1984.

Famulari, D., Nemitz, E., Di Marco, C., Phillips, G. J., Thomas, R., House, E., and Fowler, D.: Eddy-covariance measurements of nitrous oxide fluxes above a city, Agr. Forest Meteorol., in review, 2009.

Filella, I. and Penuelas, J.: Daily, weekly, and seasonal time courses of VOC concentrations in a semi-urban area near Barcelona, Atmos. Environ., 40, 7752-7769, 2006.

Friedrich, R. and Obermeier, A.: Anthropogenic Emissions of Volatile Organic Compounds, in: Reactive Hydrocarbons in the Atmosphere, edited by: Hewitt, C. N., Academic Press, California, 1-39, 1999.

Gallagher, M. W., Clayborough, R., Beswick, K. M., Hewitt, C. N., Owen, S., Moncrieff, J., and Pilegaard, K.: Assessment of a relaxed eddy accumulation for measurements of fluxes of biogenic volatile organic compounds: Study over arable crops and a mature beech forest, Atmos. Environ., 34, 2887-2899, 2000.

Grabmer, W., Graus, M., Lindinger, C., Wisthaler, A., Rappengluck, B., Steinbrecher, R., and Hansel, A.: Disjunct eddy covariance measurements of monoterpene fluxes from a norway spruce forest using PTR-MS, Int. J. Mass Spectrom., 239, 111115, 2004.

Greenberg, J. P., Guenther, A., Harley, P., Otter, L., Veenendaal, E. M., Hewitt, C. N., James, A. E., and Owen, S. M.: Eddy flux and leaf-level measurements of biogenic VOC emissions from mopane woodland of Botswana, J. Geophys. Res.-Atmos., 108(D13), 8466, doi:10.1029/2002JD002317, 2003.

Grosjean, D., Grosjean, E., and Moreira, L. F. R.: Speciated ambient carbonyls in Rio de Janeiro, Brazil, Environ. Sci. Technol. 36, 1389-1395, 2002.

Grosjean, E., Grosjean, D., Fraser, M. P., and Cass, G. R.: Air quality model evaluation data for organics. 2. C-1-C-14 carbonyls in Los Angeles air, Environ. Sci. Technol., 30, 2687-2703, 1996.

Guenther, A., Geron, C., Pierce, T., Lamb, B., Harley, P., and Fall, R.: Natural emissions of non-methane volatile organic compounds; carbon monoxide, and oxides of nitrogen from North America, Atmos. Environ., 34, 2205-2230, 2000.

Hayward, S., Hewitt, C. N., Sartin, J. H., and Owen, S. M.: Performance characteristics and applications of a proton transfer reaction-mass spectrometer for measuring volatile organic compounds in ambient air, Environ. Sci. Technol., 36, 1554-1560, 2002.

Heeb, N. V., Forss, A. M., Bach, C., Reimann, S., Herzog, A., and Jackle, H. W.: A comparison of benzene, toluene and C2-benzenes mixing ratios in automotive exhaust and in the suburban atmosphere during the introduction of catalytic converter technology to the Swiss car fleet, Atmos. Environ., 34, 31033116, 2000.

Holzinger, R., Jordan, A., Hansel, A., and Lindinger, W.: Methanol measurements in the lower troposphere near Innsbruck $\left(047^{\circ} 16^{\prime} \mathrm{N}\right.$; $\left.011^{\circ} 24^{\prime} \mathrm{E}\right)$, Austria, Atmos. Environ., 35, 2525 2532, 2001.

Horst, T. W.: A simple formula for attenuation of eddy fluxes measured with first-order-response scalar sensors, Bound.-Lay. Meteorol., 82, 219-233, 1997.

Hurst, D. F., Griffith, D. W. T., and Cook, G. D.: Trace gas emis- 
sions from biomass burning in tropical Australian savannas, J. Geophys. Res.-Atmos., 99, 16 441-16456, 1994.

Hwa, M. Y., Hsieh, C. C., Wu, T. C., and Chang, L. F. W.: Realworld vehicle emissions and VOCs profile in the Taipei tunnel located at Taiwan Taipei area, Atmos. Environ., 36, 1993-2002, 2002.

Jobson, B. T., Alexander, M. L., Maupin, G. D., and Muntean, G. G.: On-line analysis of organic compounds in diesel exhaust using a proton transfer reaction mass spectrometer (PTR-MS), Int. J. Mass Spectrom., 245, 78-89, 2005.

Karl, T. G., Spirig, C., Rinne, J., Stroud, C., Prevost, P., Greenberg, J., Fall, R., and Guenther, A.: Virtual disjunct eddy covariance measurements of organic compound fluxes from a subalpine forest using proton transfer reaction mass spectrometry, Atmos. Chem. Phys., 2, 279-291, 2002,

http://www.atmos-chem-phys.net/2/279/2002/.

Karl, T., Guenther, A., Lindinger, C., Jordan, A., Fall, R., and Lindinger, W.: Eddy covariance measurements of oxygenated volatile organic compound fluxes from crop harvesting using a redesigned proton-transfer-reaction mass spectrometer, J. Geophys. Res.-Atmos., 106, 24 157-24 167, 2001.

Kato, S., Miyakawa, Y., Kaneko, T., and Kajii, Y.: Urban air measurements using PTR-MS in Tokyo area and comparison with GC-FID measurements, Int. J. Mass Spectrom., 235, 103-110, 2004.

Kljun, N., Calanca, P., Rotachhi, M. W., and Schmid, H. P.: A simple parameterisation for flux footprint predictions, Bound.-Lay. Meteorol., 112, 503-523, 2004.

Kreuzwieser, J., Scheerer, U., and Rennenberg, H.: Metabolic origin of acetaldehyde emitted by Poplar (Populus tremula x $P$ alba) trees, J. Exp. Bot., 50, 757-765, 1999.

Kristensen, L., Mann, J., Oncley, S. P., and Wyngaard, J. C.: How close is close enough when measuring scalar fluxes with displaced sensors?, J. Atmos. Ocean. Tech., 14, 814-821, 1997.

Lee, A., Schade, G. W., Holzinger, R., and Goldstein, A. H.: A comparison of new measurements of total monoterpene flux with improved measurements of speciated monoterpene flux, Atmos. Chem. Phys., 5, 505-513, 2005,

http://www.atmos-chem-phys.net/5/505/2005/.

Lenschow, D. H., Mann, J., and Kristensen, L.: How long is long enough when measuring fluxes and other turbulence statistics, J. Atmos. Ocean. Tech., 11, 661-673, 1994.

Lenschow, D. H.: Micrometeorological techniques for measuring biosphere-atmosphere trace gas exchangei in: Biogenic Trace Gases: Measuring Emissions from Soil and Water, edited by: Matson, P. A., London, Blackwell, 126-163, 1995.

Lindinger, W., Hansel, A., and Jordan, A.: Proton-transfer-reaction mass spectrometry (PTR-MS): On-line monitoring of volatile organic compounds at pptv levels, Chem. Soc. Rev., 27, 347-354, 1998.

Lipari, F., Dasch, J. M., and Scruggs, W. F.: Aldehyde emissions from wood-burning fireplaces, Environ. Sci. Technol., 18, 326330, 1984.

Martin, C. L., Longley, I. D., Dorsey, J. R., Thomas, R. M., Gallagher M. W., and Nemitz, E.: Ultrafine particle fluxes above four major European cities, Atmos. Environ., in press, doi:10.1016/j.atmosenv.2008.10.009, 2008.

Nemitz, E., Hargreaves, K. J., McDonald, A. G., Dorsey, J. R., and Fowler, D.: Meteorological measurements of the urban heat bud- get and $\mathrm{CO}_{2}$ emissions on a city scale, Environ. Sci. Technol., 36, 3139-3146, 2002.

Oke, T. R.: Towards better scientific communication in urban climate, Theor. Appl. Climatol., 84, 179-190, 2006.

Olofsson, M., Ek-Olausson, B., Ljungstrom, E., and Langer, S.: Flux of organic compounds from grass measured by relaxed eddy accumulation technique, J. Environ. Monitor., 5, 963-970, 2003.

Park, C., Schade, G., and Boedeker, I.: VOC flux measurements using a novel relaxed eddy accumulation GC-FID system in urban Houston, Texas, Eos Trans. AGU, 89(53), Fall Meet. Suppl., Abstract A41F-0178, 2008.

Possanzini, M., Dipalo, V., Petricca, M., Fratarcangeli, R., and Brocco, D.: Measurements of lower carbonyls in Rome ambient air, Atmos. Environ., 30, 3757-3764, 1996.

Rinne, H. J. I., Delany, A. C., Greenberg, J. P., and Guenther, A. B.: A true eddy accumulation system for trace gas fluxes using disjunct eddy sampling method, J. Geophys. Res.-Atmos., 105, 24 791-24 798, 2000.

Rinne, H. J. I., Guenther, A. B., Warneke, C., de Gouw, J. A., and Luxembourg, S. L.: Disjunct eddy covariance technique for trace gas flux measurements, Geophys. Res. Lett., 28, 3139-3142, 2001.

Schween, J. H., Dlugi, R., Hewitt, C. N., and Foster, P.: Determination and accuracy of VOC-fluxes above the pine/oak forest at Castelporziano, Atmos. Environ., 31, 199-215, 1997.

Sigsby, J. E., Tejada, S., Ray, W., Lang, J. M., and Duncan, J. W.: Volatile organic-compound emissions from 46 in-use passenger cars, Environ. Sci. Technol., 21, 466-475, 1987.

Singh, H. B., Ohara, D., Herlth, D., Sachse, W., Blake, D. R., Bradshaw, J. D., Kanakidou, M., and Crutzen, P. J.: Acetone in the atmosphere - distribution, sources, and sinks, J. Geophys. Res.Atmos., 99, 1805-1819, 1994.

Spirig, C., Neftel, A., Ammann, C., Dommen, J., Grabmer, W., Thielmann, A., Schaub, A., Beauchamp, J., Wisthaler, A., and Hansel, A.: Eddy covariance flux measurements of biogenic VOCs during ECHO 2003 using proton transfer reaction mass spectrometry, Atmos. Chem. Phys., 5, 465-481, 2005, http://www.atmos-chem-phys.net/5/465/2005/.

Tani, A., Nozoe, S., Aoki, M., and Hewitt, C. N.: Monoterpene fluxes measured above a Japanese red pine forest at Oshiba plateau, Japan, Atmos. Environ., 36, 3391-3402, 2002.

Turnipseed, A. A., Pressley, S. N., Karl, T., Lamb, B., Nemitz, E., Allwine, E., Cooper, W. A., Shertz, S., and Guenther, A. B.: The use of disjunct eddy sampling methods for the determination of ecosystem level fluxes of trace gases, Atmos. Chem. Phys., 9, 981-994, 2009, http://www.atmos-chem-phys.net/9/981/2009/.

Velasco, E., Lamb, B., Pressley, S., Allwine, E., Westberg, H., Jobson, B. T., Alexander, M., Prazeller, P., Molina, L., and Molina, M.: Flux measurements of volatile organic compounds from an urban landscape, Geophys. Res. Lett., 32, L20802, doi:10.1029/2005GL023356, 2005.

Warneke, C., van der Veen, C., Luxembourg, S., de Gouw, J. A., and Kok, A.: Measurements of benzene and toluene in ambient air using proton-transfer-reaction mass spectrometry: Calibration, humidity dependence, and field intercomparison, Int. J. Mass Spectrom., 207, 167-182, 2001.

Warneke, C., Luxembourg, S. L., de Gouw, J. A., Rinne, H. J. I., Guenther, A. B., and Fall, R.: Disjunct eddy covariance measure- 
ments of oxygenated volatile organic compounds fluxes from an alfalfa field before and after cutting, J. Geophys. Res.-Atmos., 107(D8), 4067, doi:10.1029/2001JD000594, 2002.

Warneke, C., Karl, T., Judmaier, H., Hansel, A., Jordan, A., Lindinger, W., and Crutzen, P. J.: Acetone, methanol, and other partially oxidized volatile organic emissions from dead plant matter by abiological processes: Significance for atmospheric $\mathrm{HO}_{\mathrm{x}}$ chemistry, Global Biogeochem. Cy., 13, 9-17, 1999.

Wesely, M. L. and Hart, R. L.: Variability of short term eddycovariance estimates of mass exchange, in: The forest atmosphere interactions, edited by: Hutchison, B. and Hicks, B., D. Reidel publishing Company, Dortrecht, The Netherlands, 591-612, 1985

Wilkinson, M. J.: Circadian control of isoprene emissions from oil palm, Ph.D. thesis, Lancaster University, 2006.

UN ECE: Protocol to the 1979 Convention on Long-Range Transboundary Air Pollution Concerning the Control of Emissions of Volatile Organic Compounds on their Transboundary Fluxes, ECE/EB.AIR/30, United Nations Economic Commission for Europe, Geneva, Switzerland, 1991.
UN ECE: Protocol to the 1979 Convention on Long-range Transboundary Air Pollution to Abate Acidification, Eutrophication and Ground-level Ozone, United Nations Economic Commission for Europe, Geneva, Switzerland, 1999.

Zhao, J. and Zhang, R. Y.: Proton transfer reaction rate constants between hydronium ion $\left(\mathrm{H}_{3} \mathrm{O}(+)\right)$ and volatile organic compounds, Atmos. Environ., 38, 2177-2185, 2004. 